\title{
MANAJEMEN LALU LINTAS DI JALAN LINGKAR KAMPUS UNIVERSITAS BRAWIJAYA
}

\author{
Amy Wadu ${ }^{1}$ Ratna Kusumawardhani ${ }^{2}$ Ita Suherminingsih ${ }^{3}$ \\ 1 Jurusan Teknik Sipil, Politeknik Negeri Kupang \\ JI. Adi Sucipto, Penfui, Kupang \\ 2,3 Jurusan Teknik Sipil, Universitas Brawijaya \\ JI. MT. Haryono No. 167 Malang \\ E-mail: awd.ub15@gmail.com
}

\begin{abstract}
Abstrak
Universtas Brawjaya (UB) merupakan salah satu Perguruan Tinggi Negeri terkemuka di Indonesia dan terbesar di Kota Malang yang perkembangannya setiap tahun makin pesat. Akibatnya terjadi tarikan yang begitu besar ke UB sehingga menyebabkan kemacetan lalu lintas sepanjang jalur lingkar UB. Analisa kinerja lalu lintas dimulai dari pengambilan data cacah lalu lintas untuk mengetahui jumlah lalu lintas harian rata-rata yang berujung pada bagaimana tingkat pelayanan jalan tersebut atau disebut dengan LoS (Level of Service). Hasil analisa menunjukkan bahwa pada 5 tahun mendatang LoS ruas MT Haryono mencapai kategori F, sedangkan untuk simpang ITN, Gajayana dan Suhat semuanya mencapai katagori F. Sehingga diusulkan solusi memecahkan masalah ini yaitu dengan melakukan pemindahan sebagian kegiatan UB ke lokasi di luar lokasi eksisting saat ini dan perbaikan kapasitas simpang dan ruas yang akan meningkatkan kinerja ruas jalan MT Haryono menjadi E begitu juga dengan semua simpang meningkat menjadi $\mathrm{E}$.
\end{abstract}

Kata kunci: Kapasitas, Lalu Lintas, LoS, Ruas, Simpang, Volume.

\section{PENDAHULUAN}

Kota Malang adalah kota di Provinsi Jawa Timur yang dikenal dengan julukan kota pelajar. Sebagai kota pelajar tidak mengherankan jika setiap tahunnya banyak mahasiswa baru yang berasal dari luar kota Malang datang dan menetap di Malang. Hal itu dikarenakan Kota Malang memiliki sejumlah Universitas ternama baik negeri maupun swasta. Salah satu Universitas Negeri yang populer adalah Universitas Brawijaya (UB) (Dwiko, Cahyo, Arifin , \& Sulistio, 2014)

Universitas Brawijaya (UB) adalah salah satu universitas negeri yang terkemuka di Indonesia dan salah satu yang terbesar di Kota Malang. Akibat dari perkembangan UB yang semakin pesat dari tahun ke tahun maka UB membentuk tarikan dan bangkitan pergerakan bagi mahasiswa yang tersebar di wilayah Kota Malang menuju UB dan di jalan sekitar UB. Hal ini memberikan pengaruh yang besar khususnya pada kinerja jalan yang ada saat ini, seperti timbulnya kemacetan dan tidak teraturnya lalu lintas dikarenakan volume lalu lintas yang melebihi kapasitasnya. Fenomena penumpukan lalu lintas ini sering terjadi pada jam-jam sibuk (Mahendra, Khairi , Arifin, \& Sulistio, 2015).

UB memiliki 2 gerbang masuk-keluar yaitu pintu gerbang Jl. Veteran (depan Diknas) dan pintu gerbang Jl. Veteran (samping BNI UB), 2 gerbang masuk yaitu Pintu gerbang KPRI JL. MT. Haryono dan Pintu depan makam betek Jl. M. Panjaitan serta 2 gerbang keluar yaitu pintu gerbang Jl. Sukarno Hatta (Guest House UB) dan pintu gerbang Jl. Watu gong (samping ex. Stadion UB). Mahasiswa, dosen, karyawan, dan semua yang berkepentingan menggunakan fasilitas gerbang ini untuk masuk keluar, sehingga akan menimbulkan kenaikan arus kendaraan di jalan sekitar UB, yaitu Jalan Soekarno-Hatta, Jalan Veteran, Jalan Sumbersari, Jalan Gajayana, Jalan MT. Hariyono, Jalan Mayjen Panjaitan, dan Jalan Bogor Atas, yang selanjutnya disebut sebagai jalan lingkar UB.

Pintu gerbang UB di jalan Veteran merupakan pintu masuk UB yang ternyata juga jalan penghubung antara Jalan Soekarno Hatta dengan Jalan Veteran. Pada simpang gerbang UB di jalan veteran ini sangat potensial untuk menjadi titik pusat konflik lalu lintas yang saling bertemu, yaitu penyebab kemacetan akibat perubahan kapasitas serta tempat terjadinya kecelakaan. JI. Sumbersari adalah jalur terusan menuju Jl. Gajayana dan Jl. Veteran. JI. Sumbersari menghubungkan jalur selatan dalam Kota Malang menuju jalur barat (JI. MT Haryono) dan utara (JI. Soekarno Hatta). Pada 
lokasi ini sering terjadi kemacetan yang dipicu oleh badan jalan yang sempit, tidak adanya bahu jalan, adanya parking on street, serta peningkatan jumlah kendaraan saat jam pergi/pulang jam sekolah.

Yang paling mengkhawatirkan saat ini adalah kondisi lalu lintas di perempatan Soekarno-Hatta. Pintu gerbang keluar UB yang ada di jalan Soekarno-Hatta berada di titik lokasi konflik lalu lintas yang saling bertemu, baik itu arus lalu lintas dari arah jalan MT Haryono M. Panjaitan, Soekarno-Hatta, dan dari dalam kampus UB, sehingga sering terjadi kemacetan hingga terjadi blocking pada simpang ini. Sering kali diakibatkan oleh pemberhentian angkutan umum di sepanjang jalan ini dan ditambah kondisi di mana simpang ini tidak didukung oleh geometri simpang yang baik, juga terdapatnya jembatan yang jaraknya tidak jauh dari simpang tersebut, sehingga keadaan ini membuat sulit untuk memodifikasi simpang. Selain itu, UB memiliki akses jalan yang dapat menghubungkan antar ruas Jalan Veteran dan Jalan Soekarno-Hatta. Secara tidak langsung, akses jalan tersebut memberi dampak pada kapasitas simpang Soekarno-Hatta yang makin meningkat serta menimbulkan konflik pergerakan pada simpang.

Oleh karena itu diperlukan suatu konsep solusi yang efektif untuk memecahkan masalah lalu lintas pada jalan maupun simpang yang ada di lingkar UB, terutama di persimpangan Jembatan Sukarno-Hatta - ruas MT. Hariyono dan ruas Jl. Mayjend Panjaitan Malang, sehingga dapat meningkatkan kinerja simpang dan ruas yang ada

\section{METODE PENELITIAN}

Pelaksanaan pengumpulan data sangat menentukan hasil kajian terhadap Manajemen lalu Lintas jalan Lingkar UB. Metode pengumpulan data yang dilaksanakan meliputi pengumpulan data sekunder yaitu data jaringan jalan, data tata guna lahan sekitar serta pengumpulan data primer metode survei dilakukan dengan penghitungan, pengukuran dan pencatatan secara manual data inventarisasi (Inventory Survey) dan pencacahan Lalu Lintas (Traffic Counting Survey).

Kelompok Survei Inventarisasi meliputi survei-survei Inventarisasi Jaringan Jalan (Road and Traffic Control Devices Inventories), Inventarisasi Geometrik Persimpangan (Junction Geometric Inventory). Untuk survei Volume Lalu Lintas meliputi Survei Pencacahan Lalu Lintas Terklasifikasi dan Survei Volume Lalu Lintas Membelok (Classified Turning Movement Count). Sedangkan untuk kelompok Survei Tarikan Perjalanan dilakukan dengan kuisioner asal tujuan.

Analisa kinerja lalu lintas dimulai dari pengambilan data cacah lalu lintas untuk mengetahui jumlah lalu lintas harian rata-rata yang nantinya berujung pada bagaimana tingkat pelayanan jalan tersebut atau disebut dengan LoS (Level of Service)

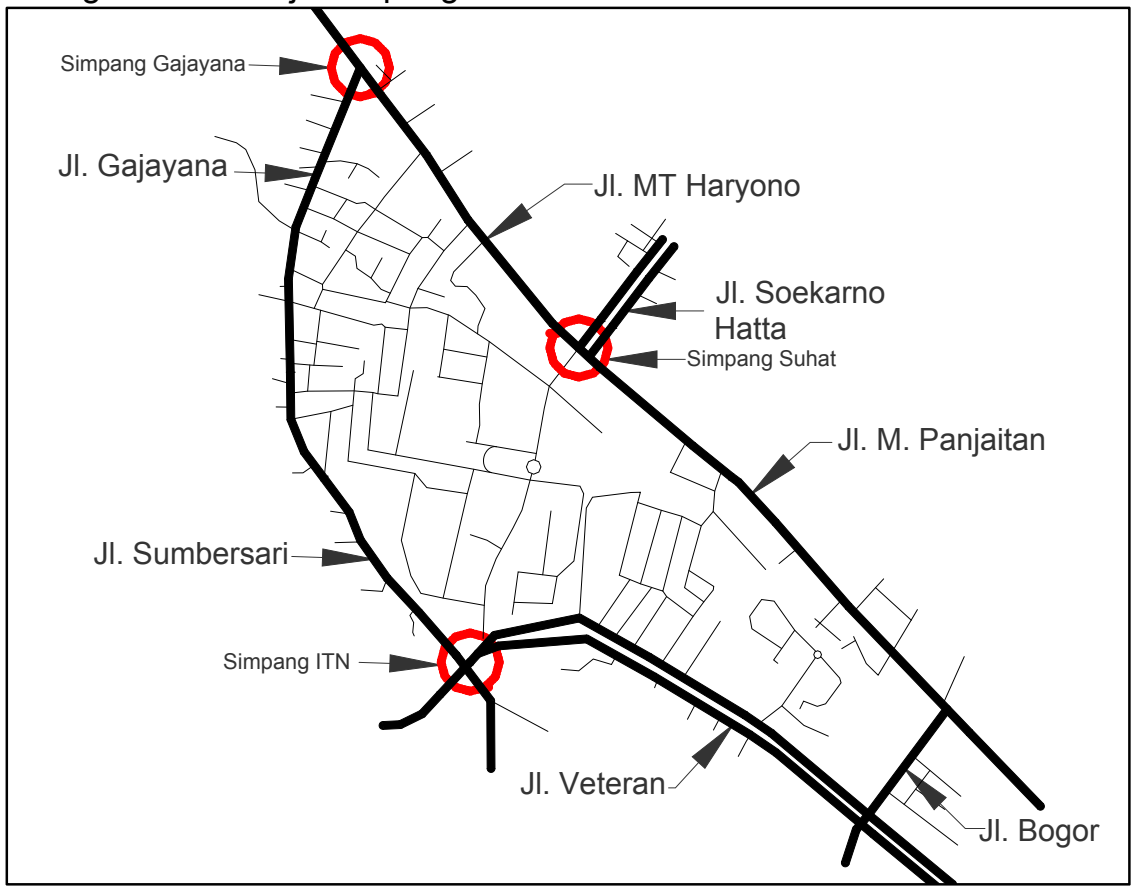

Gambar 1 Lokasi Wilayah Studi Jalan Lingkar UB 


\section{HASIL}

Data volume simpang ini diambil pada hari Senin mulai dari pukul 09.00 sampai pukul 10.00 WIB

Tabel 1 Volume Simpang

\begin{tabular}{llr}
\hline Simpang & \multicolumn{1}{c}{ Kaki Simpang } & $\begin{array}{c}\text { Volume } \\
\text { (smp/jam) }\end{array}$ \\
\hline ITN & Sumbersari & 1143.10 \\
\hline & Bendungan Sutami & 1113.62 \\
\hline & Veteran & 1310.61 \\
\hline & Bend. Sigura-gura & 1303.91 \\
\hline Gajayana & MT Haryono & 2170.95 \\
\hline & MT Haryono & 1983.34 \\
\hline Suhat & Gajayana & 1506.27 \\
\hline & MT Haryono & 1953.86 \\
\hline & Soekarno Hatta & 1618.57 \\
\hline & M. Panjaitan & 1736.76 \\
\hline
\end{tabular}

Data volume lalu lintas jalan lingkar UB ini diambil pada hari senin mulai dari pukul 09.00 sampai pukul 10.00 WIB

Tabel 2 Volume Ruas

\begin{tabular}{lrc}
\hline \multirow{2}{*}{ Ruas } & \multicolumn{2}{c}{ TOTAL } \\
\cline { 2 - 3 } & kend/jam & smp/jam \\
\hline Jln Bogor & 3881 & 1646.98 \\
\hline Jln. M. Panjaitan & 3963 & 1736.76 \\
\hline Jln. MT Haryono & 4954 & 2170.95 \\
\hline Jln. Gajayana & 4414 & 1622.86 \\
\hline Jl. Veteran & 4175 & 1646.98 \\
\hline
\end{tabular}

Survei plat matching dilakukan pada hari senin mulai dari pukul $09.10-10.10$ WIB pada 6 titik. Jumlah arus yang berhasil ditangkap melalui survei ini digambarkan seperti pada Tabel 3.

Tabel 3 Hasil Pencocokan Plat kendaraan (Plat Matching)

\begin{tabular}{lr}
\hline \multicolumn{1}{c}{ Titik } & $\begin{array}{c}\text { Jumlah } \\
\text { Kendaraan }\end{array}$ \\
\hline Suhat - MT. Haryono & 826 \\
\hline Suhat - M. Panjaitan & 1720 \\
\hline Bogor & 650 \\
\hline
\end{tabular}

\begin{tabular}{lr}
\hline \multicolumn{1}{c}{ Titik } & $\begin{array}{c}\text { Jumlah } \\
\text { Kendaraan }\end{array}$ \\
\hline MT. Haryono - Gajayana & 697 \\
\hline Gajayana - MT Haryono & 630 \\
\hline MT Haryono - Suhat & 1497 \\
\hline
\end{tabular}

\section{PEMBAHASAN}

Pada tabel 4 didapatkan kondisi eksisting level of service (LOS) ruas jalan yang ada di lingkar kampus Universitas Brawijaya yaitu pada ruas Sumbersari, Gajayana, Bogor, MT Haryono secara berturut turut memiliki nilai v/c adalah $0,49,0,57,0,53,0,68$ yang masuk dalam kriteria pelayanan $\mathrm{C}$ serta ruas Veteran yang memiliki nilai mencapai 0,96 dengan kriteria pelayanan E. Begitu pun juga dengan hasil analisa level of service (LOS) simpang pada tabel 5, dari ketiga simpang pada area lingkar Universitas Brawijaya semuanya pada kondisi $E$ dengan tundaan pada simpang ITN, Gajayana, dan Suhat secara berturut-turut adalah 59,75 detik/kend, 58,33 detik/kend, 58,67 detik/kend. Hal ini menunjukkan bahwa tingkat pelayanan rendah, suatu akibat dari arus lalu lintas yang lebih buruk dalam kaitannya dengan karakteristik pelayanan (Wikrama, 2011)

Dari hasil analisa plat matching yang didapat, maka didapatkan persentase penyebaran ke ruas jalan lain di lingkar UB. Dari tabel 5 menunjukkan, tingkat penyebaran kendaraan ke ruas jalan lingkar UB paling tinggi cuma mencapai $13,65 \%$ yang merupakan kendaraan dari jalan Gajayana menuju jalan Soekarno Hatta, sedangkan untuk kendaran dari arah jalan Soekarno Hatta ke jalan Bogor dan jalan Sekarno Hatta ke jalan Gajayana adalah $8,31 \%$ dan $10,65 \%$. Ini menggambarkan kalau keberadaan Universitas Brawijaya memberi dampak tarikan yang sangat besar bagi pergerakan kendaraan.

Tabel 4 Level of Service (LoS) Ruas Eksisting

\begin{tabular}{cccc}
\hline Ruas & Kapasitas & v/c & LOS \\
\hline Veteran & 1723.55 & 0.96 & E \\
\hline Sumbersari & 3164.39 & 0.49 & $\mathrm{C}$ \\
\hline Gajayana & 2853.14 & 0.57 & $\mathrm{C}$ \\
\hline Bogor & 3085.37 & 0.53 & $\mathrm{C}$ \\
\hline MT Haryono & 3200.82 & 0.68 & $\mathrm{C}$ \\
\hline
\end{tabular}


Tabel 5 Level of Service (LOS) Simpang Eksisting

\begin{tabular}{|c|c|c|c|c|}
\hline \multirow[t]{2}{*}{ Simpang } & \multirow{2}{*}{$\begin{array}{c}\text { Kaki } \\
\text { Simpang }\end{array}$} & $\begin{array}{r}\mathrm{V} \\
\mathrm{Tu} \\
\text { (det }\end{array}$ & $\begin{array}{l}\text { ktu } \\
\text { daan } \\
\text { (kend) }\end{array}$ & \multirow[t]{2}{*}{ LOS } \\
\hline & & & $\begin{array}{l}\text { Rata- } \\
\text { rata }\end{array}$ & \\
\hline \multirow[t]{4}{*}{ ITN } & Sumbersari & 58 & 59.75 & $E$ \\
\hline & $\begin{array}{c}\text { Bendungan } \\
\text { Sutami }\end{array}$ & 58 & & \\
\hline & Veteran & 65 & & \\
\hline & $\begin{array}{c}\text { Bend. } \\
\text { Sigura-gura }\end{array}$ & 58 & & \\
\hline \multirow[t]{3}{*}{ Gajayana } & $\begin{array}{c}\text { MT } \\
\text { Haryono }\end{array}$ & 52 & 58.33 & $E$ \\
\hline & $\begin{array}{c}\text { MT } \\
\text { Haryono }\end{array}$ & 54 & & \\
\hline & Gajayana & 69 & & \\
\hline \multirow[t]{3}{*}{ Suhat } & $\begin{array}{c}\text { MT } \\
\text { Haryono }\end{array}$ & 55 & 58.67 & $E$ \\
\hline & $\begin{array}{c}\text { Soekarno } \\
\text { Hatta }\end{array}$ & 69 & & \\
\hline & $\begin{array}{c}\text { M. } \\
\text { Panjaitan }\end{array}$ & 52 & & \\
\hline
\end{tabular}

Tabel 6 Penyebaran Kendaraan

\begin{tabular}{ccc}
\hline $\begin{array}{c}\text { Ruas } \\
\text { Jalan }\end{array}$ & $\begin{array}{c}\text { Jumlah } \\
\text { kendaraan }\end{array}$ & Presentase \\
\hline $\begin{array}{c}\text { Suhat - } \\
\text { Bogor }\end{array}$ & 143 & $8.31 \%$ \\
\hline $\begin{array}{c}\text { Gajayana } \\
\text { - Suhat }\end{array}$ & 86 & $13.65 \%$ \\
\hline $\begin{array}{c}\text { Suhat - } \\
\text { Gajayana }\end{array}$ & 88 & $10.65 \%$ \\
\hline
\end{tabular}

Setiap tahun, Kota Malang mengalami pertumbuhan kendaraan, sehingga diprediksikan volume kendaraan yang ada akan bertambah. Diproyeksikan pertumbuhan kendaraan yang ada setiap tahunnya adalah $5 \%$. Dari hasil analisa yang dilakukan, dapat dilihat pada tabel 5, simpang ITN, Gajayana, dan Suhat secara berutut-turut memiliki tundaan sebesar 59,75 detik/kend dengan kriteria LOS E, 74,45 detik/kend, dan 74,88 detik/kend dengan kriteria LOS F. Hal ini menunjukkan bahwa pada 5 tahun mendatang arus pada simpang akan mengalami ketidak stabilan, antrian kendaraan yang berhenti secara bergantian dan dapat mengakibatkan macet total (Pradipta, Purba, Wicaksono, \& Indriastuti, 2017).

Pada tabel 7 kondisi ruas yang berada di lingkar kampus Universitas Brawijaya pada 5 tahun mendatang juga akan mempunyai tingkat pelayanan yang rendah. Dari hasil analisa menunjukkan bahwa jalan Gajayana dan jalan Veteran tingkat pelayanannya masuk dalam kategori F. Begitu juga dengan kondisi simpang pada 5 tahun yang ditunjukkan pada tabel 8 LOS simpang ITN masuk dalam kategori E sedangkan simpang Gajayana dan Suhat masuk dalam kategori F. Ini menunjukkan kondisi arus lalu lintas pada 5 tahun mendatang akan terhambat di antaranya berhenti, antrian tinggi, bahkan macet total (Tamin, 2000), sedangkan untuk jalan Sumbersari, jalan Bogor, dan MT Haryono memiliki tingkat pelayanan kategori $\mathrm{C}$ yang artinya arus masih stabil tapi operasi gerak kendaraan mulai dipengaruhi kendaraan lain dan pengemudi terbatas dalam memilih kecepatan (Tamin, 2000). Dari analisa kondisi lalu lintas 5 tahun mendatang, maka perlu disiapkan skenario alternatif untuk dapat menjadi solusi permasalahan kondisi lalu lintas pada 5 tahun mendatang.

Tabel 7 Level of Service (LOS) Ruas Kondisi 5 tahun mendatang

\begin{tabular}{cccc}
\hline Ruas & Volume & v/c & LOS \\
\hline Veteran & 2102.01 & 1.22 & $\mathrm{~F}$ \\
\hline Sumbersari & 1990.84 & 0.63 & $\mathrm{C}$ \\
\hline Gajayana & 2295.28 & 1.42 & $\mathrm{~F}$ \\
\hline Bogor & 2071.22 & 0.73 & $\mathrm{C}$ \\
\hline MT Haryono & 2102.01 & 0.68 & $\mathrm{C}$
\end{tabular}

Tabel 8 Level of Service (LOS) Simpang Kondisi 5 tahun mendatang

\begin{tabular}{|c|c|c|c|c|}
\hline \multirow[t]{2}{*}{ Simpang } & \multirow{2}{*}{$\begin{array}{c}\text { Kaki } \\
\text { Simpang }\end{array}$} & \multicolumn{2}{|c|}{$\begin{array}{l}\text { Waktu } \\
\text { Tundaan } \\
\text { (det/kend) }\end{array}$} & \multirow[t]{2}{*}{ LOS } \\
\hline & & & $\begin{array}{l}\text { Rata- } \\
\text { rata }\end{array}$ & \\
\hline \multirow[t]{4}{*}{ ITN } & Sumbersari & 74.02 & 59.75 & $E$ \\
\hline & $\begin{array}{l}\text { Bendungan } \\
\text { Sutami }\end{array}$ & 74.02 & & \\
\hline & Veteran & 82.96 & & \\
\hline & $\begin{array}{l}\text { Bend. } \\
\text { Sigura-gura }\end{array}$ & 74.02 & & \\
\hline \multirow[t]{3}{*}{ Gajayana } & $\begin{array}{l}\text { MT } \\
\text { Haryono }\end{array}$ & 66.37 & 74.45 & $\mathrm{~F}$ \\
\hline & $\begin{array}{l}\text { MT } \\
\text { Haryono }\end{array}$ & 68.92 & & \\
\hline & Gajayana & 88.06 & & \\
\hline \multirow[t]{3}{*}{ Suhat } & $\begin{array}{l}\text { MT } \\
\text { Haryono }\end{array}$ & 70.20 & 74.88 & $\mathrm{~F}$ \\
\hline & $\begin{array}{l}\text { Soekarno } \\
\text { Hatta }\end{array}$ & 88.06 & & \\
\hline & $\begin{array}{l}\text { M. } \\
\text { Panjaitan }\end{array}$ & 66.37 & & \\
\hline
\end{tabular}




\section{Skenario 1 : Penambahan Kapasitas Jalan}

Skenario pertama yang dapat digunakan untuk meningkatkan tingkat pelayanan adalah penambahan kapasitas. Penambahan kapasitas dapat dilakukan dengan penghilangan parkir on street, larangan pedagang kaki lima berjualan di badan jalan, larangan angkutan umum menunggu penumpang, dll. Skenario ini tidak membutuhkan biaya karena hanya memerlukan penertiban di jalan lingkar UB.

Kontrol 'on street parking' dilakukan di sepanjang ruas jalan MT Haryono, Sumbersari, Gajayana dengan memberlakukan perbaikan sempadan bangunan, area parkir khusus yang terpusat (untuk MT Haryono yang memiliki fungsi arteri sekunder I) agar bukaan langsung ke jalan raya dapat diatur minimal 100 meter

Dari tabel 4 dapat dilihat bahwa untuk skenario penambahan kapasitas ini diperoleh tingkat pelayanan untuk jalan Bogor, $M$. Panjaitan, Gajayana, Sumbersari secara berturut-turut adalah 0,57, 0,58, 0,60, dan 0,52 yang masuk dalam tingkat pelayanan kategori C. Sedangkan untuk jalan MT Haryono dan Veteran didapatkan 0,72 dan 1,02 dengan masing-masingnya masuk dalam tingkat pelayanan kategori $\mathrm{D}$ dan $\mathrm{F}$.

Dari tabel 5 dapat dilihat bahwa untuk skenario penambahan kapasitas ini diperoleh tundaan rata-rata untuk simpang ITN, Gajayana, dan Suhat secara berturut-turut adalah $63,55,62,04,62,40$ detik/kendaraan, dengan demikian kondisi semua simpang ini masuk dalam tingkat pelayanan kategori $\mathrm{F}$.

Tabel 9 Kondisi Ruas Dengan Skenario 1

\begin{tabular}{cccc}
\hline Ruas & Kapasitas & v/c & LOS \\
\hline Bogor & 3702.44 & 0.57 & $\mathrm{C}$ \\
\hline M. Panjaitan & 3840.98 & 0.58 & $\mathrm{C}$ \\
\hline MT Haryono & 3840.98 & 0.72 & $\mathrm{D}$ \\
\hline Gajayana & 3423.76 & 0.60 & $\mathrm{C}$ \\
\hline Veteran & 2068.26 & 1.02 & $\mathrm{~F}$ \\
\hline Sumbersari & 3797.26 & 0.52 & $\mathrm{C}$ \\
\hline
\end{tabular}

Tabel 10 Kondisi Simpang Dengan Skenario 1

\begin{tabular}{|c|c|c|c|c|}
\hline \multirow{2}{*}{ Simpang } & \multirow{2}{*}{$\begin{array}{c}\text { Kaki } \\
\text { Simpang }\end{array}$} & \multicolumn{2}{|c|}{$\begin{array}{l}\text { Waktu } \\
\text { Tundaan }\end{array}$} & \multirow[t]{2}{*}{ LOS } \\
\hline & & & $\begin{array}{l}\text { Rata- } \\
\text { rata }\end{array}$ & \\
\hline \multirow[t]{3}{*}{ ITN } & Sumbersari & 61.69 & 63.55 & $\mathrm{~F}$ \\
\hline & $\begin{array}{c}\text { Bendungan } \\
\text { Sutami }\end{array}$ & 61.69 & & \\
\hline & Veteran & 69.13 & & \\
\hline
\end{tabular}

\begin{tabular}{|c|c|c|c|c|}
\hline \multirow{2}{*}{ Simpang } & \multirow{2}{*}{$\begin{array}{c}\text { Kaki } \\
\text { Simpang }\end{array}$} & \multicolumn{2}{|c|}{$\begin{array}{c}\text { Waktu } \\
\text { Tundaan }\end{array}$} & \multirow[t]{2}{*}{ LOS } \\
\hline & & & $\begin{array}{l}\text { Rata- } \\
\text { rata }\end{array}$ & \\
\hline & $\begin{array}{c}\text { Bend. } \\
\text { Sigura- } \\
\text { gura }\end{array}$ & 61.69 & & \\
\hline \multirow{3}{*}{ Gajayana } & $\begin{array}{c}\text { MT } \\
\text { Haryono }\end{array}$ & 55.31 & 62.04 & $\mathrm{~F}$ \\
\hline & $\begin{array}{c}\text { MT } \\
\text { Haryono }\end{array}$ & 57.43 & & \\
\hline & Gajayana & 73.39 & & \\
\hline \multirow[t]{3}{*}{ Suhat } & $\begin{array}{c}\text { MT } \\
\text { Haryono }\end{array}$ & 58.50 & 62.40 & $\mathrm{~F}$ \\
\hline & $\begin{array}{c}\text { Soekarno } \\
\text { Hatta }\end{array}$ & 73.39 & & \\
\hline & $\begin{array}{c}\text { M. } \\
\text { Panjaitan }\end{array}$ & 55.31 & & \\
\hline
\end{tabular}

\section{Skenario 2 : Pengalihan sebagian aktivitas Universitas Brawijaya ke lokasi lain}

Skenario kedua yang dapat digunakan untuk meningkatkan tingkat pelayanan adalah pengalihan sebagian aktivitas pada Kampus UB ke lokasi lain. Hal ini direkomendasikan atas dasar hasil survei plat matching, adanya persentasi kendaraan yang mengalami tarikan ke kampus UB atau sekitarnya yang di atas $85 \%$, maka pemindahan sebagian kampus ke lokasi lain menjadi langkah alternatif selanjutnya. Dilakukannya pemindahan ke lokasi lain ini pasti akan berdampak pada aktivitas di sekitar UB, misalnya mahasiswa yang kos di sekitar kampus juga akan ikut pindah dekat lokasi yang baru, dengan demikian terjadi pengurangan bangkitan maupun tarikan kendaraan

Tabel 11 Kondisi Ruas Skenario 2

\begin{tabular}{cccc}
\hline Ruas & Volume & v/c & LOS \\
\hline Bogor & 1716.50 & 0.56 & $\mathrm{C}$ \\
\hline M. Panjaitan & 1810.07 & 0.57 & $\mathrm{C}$ \\
\hline MT Haryono & 2262.59 & 0.71 & $\mathrm{C}$ \\
\hline Gajayana & 1691.36 & 0.59 & $\mathrm{C}$ \\
\hline Veteran & 1716.50 & 0,996 & $\mathrm{E}$ \\
\hline Sumbersari & 1626.16 & 0.51 & $\mathrm{C}$ \\
\hline
\end{tabular}

Tabel 12 Kondisi Simpang Skenario 2

\begin{tabular}{|c|c|c|c|c|}
\hline \multirow{2}{*}{ Simpang } & \multirow{2}{*}{$\begin{array}{c}\text { Kaki } \\
\text { Simpang }\end{array}$} & \multicolumn{2}{|c|}{ Waktu Tundaan } & \multirow[b]{2}{*}{ LOS } \\
\hline & & & $\begin{array}{l}\text { Rata- } \\
\text { rata }\end{array}$ & \\
\hline ITN & Sumbersari & 60.45 & 62.27 & $\mathrm{~F}$ \\
\hline & $\begin{array}{c}\text { Bendungan } \\
\text { Sutami }\end{array}$ & 60.45 & & \\
\hline
\end{tabular}


Amy Wadu ${ }^{1}$ Ratna Kusumawardhani ${ }^{2}$ Ita Suherminingsih ${ }^{3}$

\begin{tabular}{|c|c|c|c|c|}
\hline \multirow{2}{*}{ Simpang } & \multirow{2}{*}{$\begin{array}{c}\text { Kaki } \\
\text { Simpang }\end{array}$} & \multicolumn{2}{|c|}{ Waktu Tundaan } & \multirow[b]{2}{*}{ LOS } \\
\hline & & & $\begin{array}{l}\text { Rata- } \\
\text { rata }\end{array}$ & \\
\hline & Veteran & 67.74 & & \\
\hline & $\begin{array}{l}\text { Bend. } \\
\text { Sigura- } \\
\text { gura }\end{array}$ & 60.45 & & \\
\hline \multirow[t]{3}{*}{ Gajayana } & $\begin{array}{c}\text { MT } \\
\text { Haryono }\end{array}$ & 54.20 & 60.80 & $\mathrm{~F}$ \\
\hline & $\begin{array}{c}\text { MT } \\
\text { Haryono }\end{array}$ & 56.28 & & \\
\hline & Gajayana & 71.91 & & \\
\hline \multirow[t]{3}{*}{ Suhat } & $\begin{array}{c}\text { MT } \\
\text { Haryono }\end{array}$ & 57.32 & 61.14 & $\mathrm{~F}$ \\
\hline & $\begin{array}{c}\text { Soekarno } \\
\text { Hatta }\end{array}$ & 71.91 & & \\
\hline & $\begin{array}{c}\text { M. } \\
\text { Panjaitan }\end{array}$ & 54.20 & & \\
\hline
\end{tabular}

\section{Skenario 3 : dengan penambahan kapasitas dan pengalihan sebagian aktivitas}

Skenario ketiga merupakan gabungan antara skenario 1 dan skenario 2. Pada tabel 13 LOS untuk kenario penambahan kapasitas dan pengalihan sebagian aktivitas kampus UB ini diperoleh tingkat pelayanan untuk jalan Bogor, M. Panjaitan, MT Haryono, dan Gajayana secara berturut-turut adalah 0,46, 0,47, 0,59, dan 0,49 yang masuk dalam tingkat pelayanan kategori C. Sedangkan untuk jalan Sumbersari dan Veteran didapatkan 0,83 dan 0,43 yang masing-masing masuk dalam tingkat pelayanan kategori $\mathrm{B}$ dan $\mathrm{D}$. Begitu juga pada tabel 14 untuk skenario pengalihan aktivitas kampus UB ini diperoleh tundaan rata-rata untuk simpang ITN, Gajayana, dan Suhat secara berturut-turut adalah $51,89,50,66$, dan 50,95 detik/kendaraan, dengan demikian kondisi semua simpang ini masuk dalam tingkat pelayanan kategori $\mathrm{E}$ yang artinya tingkat pelayanannya meningkat dari skenario 1 dan skenario 2 .

Tabel 13 Kondisi Ruas Skenario 3

\begin{tabular}{cccc}
\hline Ruas & Volume & v/c & LOS \\
\hline Bogor & 1716.50 & 0.46 & $\mathrm{C}$ \\
\hline M. Panjaitan & 1810.07 & 0.47 & $\mathrm{C}$ \\
\hline MT Haryono & 2262.59 & 0.59 & $\mathrm{C}$ \\
\hline Gajayana & 1691.36 & 0.49 & $\mathrm{C}$ \\
\hline Veteran & 1716.50 & 0.83 & $\mathrm{D}$ \\
\hline Sumbersari & 1626.16 & 0.43 & $\mathrm{~B}$ \\
\hline
\end{tabular}

Tabel 14 Kondisi Simpang Skenario 3

\begin{tabular}{|c|c|c|c|c|}
\hline \multirow{2}{*}{ Simpang } & \multirow{2}{*}{$\begin{array}{c}\text { Kaki } \\
\text { Simpang }\end{array}$} & \multicolumn{2}{|c|}{ Waktu Tundaan } & \multirow[b]{2}{*}{ LOS } \\
\hline & & & $\begin{array}{l}\text { Rata- } \\
\text { rata }\end{array}$ & \\
\hline \multirow[t]{4}{*}{ ITN } & Sumbersari & 50.37 & 51.89 & $E$ \\
\hline & $\begin{array}{l}\text { Bendungan } \\
\text { Sutami }\end{array}$ & 50.37 & & \\
\hline & Veteran & 56.45 & & \\
\hline & $\begin{array}{l}\text { Bend. } \\
\text { Sigura-gura }\end{array}$ & 50.37 & & \\
\hline \multirow[t]{3}{*}{ Gajayana } & MT Haryono & 45.16 & 50.66 & $\mathrm{E}$ \\
\hline & MT Haryono & 46.90 & & \\
\hline & Gajayana & 59.93 & & \\
\hline \multirow[t]{3}{*}{ Suhat } & MT Haryono & 47.77 & 50.95 & $\mathrm{E}$ \\
\hline & $\begin{array}{l}\text { Soekarno } \\
\text { Hatta }\end{array}$ & 59.93 & & \\
\hline & M. Panjaitan & 45.16 & & \\
\hline
\end{tabular}

\section{PENUTUP}

Kinerja lalu lintas eksisting saat ini adalah mayoritas $\mathrm{E}$ untuk simpang dan $\mathrm{C}$ untuk ruas. Prediksi masa depan untuk kondisi 5 tahun tetap adalah kinerja lalu lintas adalah $\mathrm{C}$ dan $F$ untuk simpang. Akar masalah menunjukkan permasalahan yang terjadi disebabkan adanya tarikan besar dari UB dan intensitas guna lahan yang sangat tinggi di lingkar UB. Sehingga rekomendasi untuk manajemen lalu lintas menurut hasil perhitungan yang sudah dilakukan yang terpilih adalah alternatif 3 yaitu adanya pemindahan sebagian kegiatan UB ke lokasi di luar lokasi eksisting saat ini dan perbaikan kapasitas simpang dan ruas.

\section{DAFTAR PUSTAKA}

Dwiko, A., Cahyo, A., Arifin , M. Z., \& Sulistio, H. (2014). Kajian Volume Serta Kinerja Lalu Lintas JI.Mt.Haryonojembatan Soekarno Hatta-JI.M.PanjaitanJl.Bogor Atas-Jl.Veteran Dan JI.Gajayana. Jurnal Mahasiswa Jurusan Teknik Sipil, 1-10.

Mahendra, A. D., Khairi , M., Arifin, M. Z., \& Sulistio, H. (2015). Kajian Persebaran Lalu Lintas Akibat Pembongkaran Jembatan Soekarno Hatta. Jurnal Mahasiswa Jurusan Teknik Sipil, 1-11. 
Pradipta, R. E., Purba, T., Wicaksono, Y. I., \& Indriastuti, A. K. (2017). Evaluasi Kinerja Simpang Bersinyal Dan Flyover Di Bundaran Kalibanteng. Jurnal Karya Teknik Sipil, 263-274.

Tamin, O. Z. (2000). Perencanaan dan Pemodelan Transportasi. Bandung: Penerbit ITB.

Wikrama, J. (2011). Analisis Kinerja Simpang Bersinyal (Studi Kasus Jalan Teuku Umar Barat - Jalan Gunung Salak) . Jurnal IImiah Teknik Sipil, 56-71. 